\title{
Blood pressure at age 60-65 versus age 70-75 and vascular dementia: a population based observational study
}

\author{
Mingkai Peng ${ }^{1 *}$, Guanmin Chen ${ }^{2}$, Karen L. Tang ${ }^{3}$, Hude Quan ${ }^{1}$, Eric E. Smith ${ }^{4}$, Peter Faris ${ }^{2}$, Vladimir Hachinski ${ }^{5}$ \\ and Norm R. C. Campbell ${ }^{6}$
}

\begin{abstract}
Background: Vascular dementia $(\mathrm{VaD})$ is the second most common form of dementia. However, there were mixed evidences about the association between blood pressure (BP) and risk of $\mathrm{VaD}$ in midlife and late life and limited evidence on the association between pulse pressure and $\mathrm{VaD}$.

Methods: This is a population-based observational study. 265,897 individuals with at least one BP measurement between the ages of 60 to 65 years and 211,116 individuals with at least one BP measurement between the ages of 70 to 75 years were extracted from The Health Improvement Network in United Kingdom. Blood pressures were categorized into four groups: normal, prehypertension, stage 1 hypertension, and stage 2 hypertension. Cases of VaD were identified from the recorded clinical diagnoses. Multivariable survival analysis was used to adjust other confounders and competing risk of death. All the analysis were stratified based on antihypertensive drug use status. Multiple imputation was used to fill in missing values.
\end{abstract}

Results: After accounting for the competing risk of death and adjustment for potential confounders, there was an association between higher BP levels in the age 60-65 cohort with the risk of developing VaD (hazard ratio [HR] 1.53 (95\% confidence interval: 1.04, 2.25) for prehypertension, $1.90(1.30,2.78)$ for stage 1 hypertension, and $2.19(1.48,3.26)$ for stage 2 hypertension) in the untreated group. There was no statistically significant association between BP levels and VaD in the treated group in the age 60-65 cohort and age 70-75 cohort. Analysis on Pulse Pressure (PP) stratified by blood pressure level showed that PP was not independently associated with VaD.

Conclusion: High BP between the ages of 60 to 65 years is a significant risk for VaD in late midlife. Greater efforts should be placed on early diagnosis of hypertension and tight control of BP for hypertensive patients for the prevention of $\mathrm{VaD}$.

Keywords: Population based observational study, Blood pressure, Vascular dementia, Pulse pressure

\section{Background}

Hypertension and dementia are common disorders in the elderly. Among people aged 60 years and over, the prevalence is estimated to be around 5 to $7 \%$ for dementia and over $50 \%$ for hypertension $[1,2]$. Vascular dementia $(\mathrm{VaD})$ caused by a variety of vascular diseases is one of the most common forms of dementia [3]. There are several different sets of clinical diagnostic criteria for $\mathrm{VaD}$, though each set tends to consist of a combination of history of

\footnotetext{
* Correspondence: mpeng@ucalgary.ca

1 Department of Community Health Sciences, University of Calgary, Calgary

T2N 1N4, Canada

Full list of author information is available at the end of the article
}

ischemic stroke, temporal relationship between onset of dementia and stroke, and/or evidence of cerebrovascular disease. High blood pressure (BP), or hypertension, is the leading risk factor for stroke and many other vascular diseases [4]. Thus, hypertension likely plays an important role in the development of $\mathrm{VaD}$, though this association remains unclear [5].

The association between $\mathrm{BP}$ and dementia may be age dependent, [6, 7] with high BP at midlife (age 40-64 years) being associated with an increased risk for $\mathrm{VaD}[5,8]$. In contrast, there is no consensus on the association between $\mathrm{BP}$ and dementia in those aged 75 and above. A history of hypertension at age 75 or over is not consistently a risk 
factor for $\mathrm{VaD}$, with some studies even reporting an inverse association between level of blood pressure and risk of $\mathrm{VaD}[9,10]$. Previous studies have been focused on the association of systolic and diastolic BP with dementia. Pulse pressure (PP) is the difference between the systolic and diastolic pressure readings, and is a measure of arterial stiffness. The pulsatile component of BP and high PP has been shown to increase the risk of cardiovascular disease and total mortality [11]. The association of PP with dementia remains unclear.

Electronic medical records (EMR) contain rich clinical information, in which more than $50 \%$ of patients have at least 2 blood pressure measurements [12]. EMR also provides a population-based sample with the ability to follow patients for long periods of time. The objective of this study was to investigate the association of BP and PP levels in late midlife and late-life with the risk of vascular dementia using United Kingdom (UK) primary care data. We developed two separate study cohorts (aged 60-65 and aged 70-75) to elucidate whether there is an agedependent relationship of blood pressure with $\mathrm{VaD}$.

\section{Methods}

\section{Data source}

This study was conducted using The Health Improvement Network (THIN) that is one of the largest source of continuous primary care data in United Kingdom (UK). Prospective data collection in THIN started in 2002 with data dating back to the early 1980s. THIN received anonymized patient data from general practice computer systems used for patient management and research purposes. It is a primary care EMR database with the patient information recorded during routine physician visits, such as diagnoses, prescriptions, physiological measurements, diagnostic tests, lifestyle information, and referrals to secondary care. THIN holds anonymized longitudinal medical records for over 11.1 million individuals with more than 3.7 million who remain actively registered. THIN is demographically representative of UK [13]. The Read clinical classification, developed in the UK for primary care, was used in THIN to code clinical information [14].

\section{Study population}

We conducted a retrospective population-based cohort study. Two independent study cohorts were created. The first cohort included individuals with at least one blood pressure measurement between the ages of 60 to 65 , and the second cohort included individuals with at least one blood pressure measurement between the ages of 70 and 75 . We used the date of last blood pressure measurement within 60 to 65 or 70 to 75 as the index date of follow-up. To ensure an adequate period of follow-up, we only included individuals with an index date between the years
1989 and 2004 and who have registered in THIN for at least 2 years before the index date. All individuals were followed until they experienced the any one of the following: diagnosis of $\mathrm{VaD}$, died, left the THIN database, or the follow-up ended (14 May 2012). Anyone with a diagnosis of $\mathrm{VaD}$ before the index date was excluded.

\section{Blood pressure categories}

We extracted all the blood pressure values measured within 2 years prior to the index date and calculated the average systolic (SBP) and diastolic blood pressure (DBP). BP (measured in $\mathrm{mmHg}$ ) were classified into 4 categories: normal: $\mathrm{SBP}<120$ and $\mathrm{DBP}<80$; prehypertension: $120 \leq \mathrm{SBP}<140$ or $80 \leq \mathrm{DBP}<90$; stage 1 hypertension: $140 \leq \mathrm{SBP}<160$ or $90 \leq \mathrm{DBP}<100$; stage 2 hypertension: SBP $\geq 160$ or $\mathrm{DBP} \geq 100$ according to the criteria of the seventh report of Joint National committee on the Prevention, Detection, Evaluation and Treatment of High Blood Pressure (JNC-7) [15]. Individuals were classified into the higher category if there was a difference in categories based on diastolic and systolic blood pressure. We categorized PP (measured in $\mathrm{mmHg}$ ) into 4 categories: $\mathrm{PP} \leq 50,50<\mathrm{PP} \leq 60,60<\mathrm{PP} \leq 70$, and $70<\mathrm{PP}$.

\section{Ascertainment of vascular dementia}

We ascertained the cases of $\mathrm{VaD}$ using the diagnosis codes E004 - arteriosclerotic dementia/multi-infarct dementia and Eu01 - vascular dementia/arteriosclerotic dementia. The index date of $\mathrm{VaD}$ was the earliest diagnosis date recorded in the THIN. Diagnosis information in THIN are generally well recorded and have been successfully used in several studies on dementia [16, 17]. According to the diagnosis guideline, the general practitioners made a diagnosis of dementia through the following steps: patient history review, cognitive impairment assessment through a specific test (e.g mini-mental state examination test), referral to a specialist, and/or assessment based on neuroimaging techniques [18]. The coding of dementia in EMR data shows good agreement with physician diagnosis and hospital admission data $[19,20]$.

\section{Other risk factors}

Individuals with the diagnosis of diabetes, stroke, and depression prior to the index date were identified using the Read codes listed in Quality and Outcome Framework- National Health Science (QOF-NHS). History of head injury and Parkinson's disease was identified based on Read codes found in a text search in the Read code dictionary [21]. All codes used in this study are listed in Additional file 1: Table S1. We also extracted smoking status of individuals using the following three classifications: never smoked, former smoker, and current smoker. Body mass index (BMI) was calculated based on the recorded weight and 
height. We used the median height recorded after the age of 25 and the most recent weight recorded within 5 years prior to the index date of follow-up. BMI were classified into three categories: normal $(<25)$, overweight $(25 \leq$ and $<30)$, and obesity $(\geq 30)$.

We extracted all the antihypertensive drugs information (See Additional file 1: Table S2 for drug list) 1 year before the study index date. Anyone who had at least one antihypertensive drug prescription were assigned as the treated group.

\section{Statistical analysis}

Descriptive statistics were used to compare the demographics and clinical conditions for patients with different blood pressure levels. We explored the association of blood pressure and vascular dementia by estimating age and sex standardized incidence rates of 13 SBP categories and 7 DBP categories. Blood pressure was categorized for every $5 \mathrm{mmHg}$ interval from 115 to $170 \mathrm{mmHg}$ for SBP and from 70 to $95 \mathrm{mmHg}$ for DBP. We categorized individuals with SBP/DBP below or above the ranges as the first and last categories (for example, for SBP, $<115$ or
$>170 \mathrm{mmHg}$ ). The mean blood pressure value for each category was calculated. The cumulative incidence of vascular dementia was estimated using the product-limit life-table method, accounting for the competing risk of death [22]. Proportional subdistribution hazard model was used to estimate the association of blood pressure levels and $\mathrm{PP}$ with risk of $\mathrm{VaD}$, while treating death as a competing risk [23]. Stratified analysis on PP at each BP level was conducted using the proportional hazard model. Adjustment for potential confounders including age, sex, smoking status, BMI categories, and history of diabetes, stroke, depression, and Parkinson's disease was performed in all models. All of the analyses were stratified by drug use status (treated and untreated).

The variables of smoking status and BMI had missing values. We approached this issue using two different methods. First, models were developed using only the observations without missing values. Second, we used the multiple imputation method to impute ten versions of complete dataset. The multiple imputation allows for the uncertainty about the missing data by creating several different plausible imputed data sets and appropriately
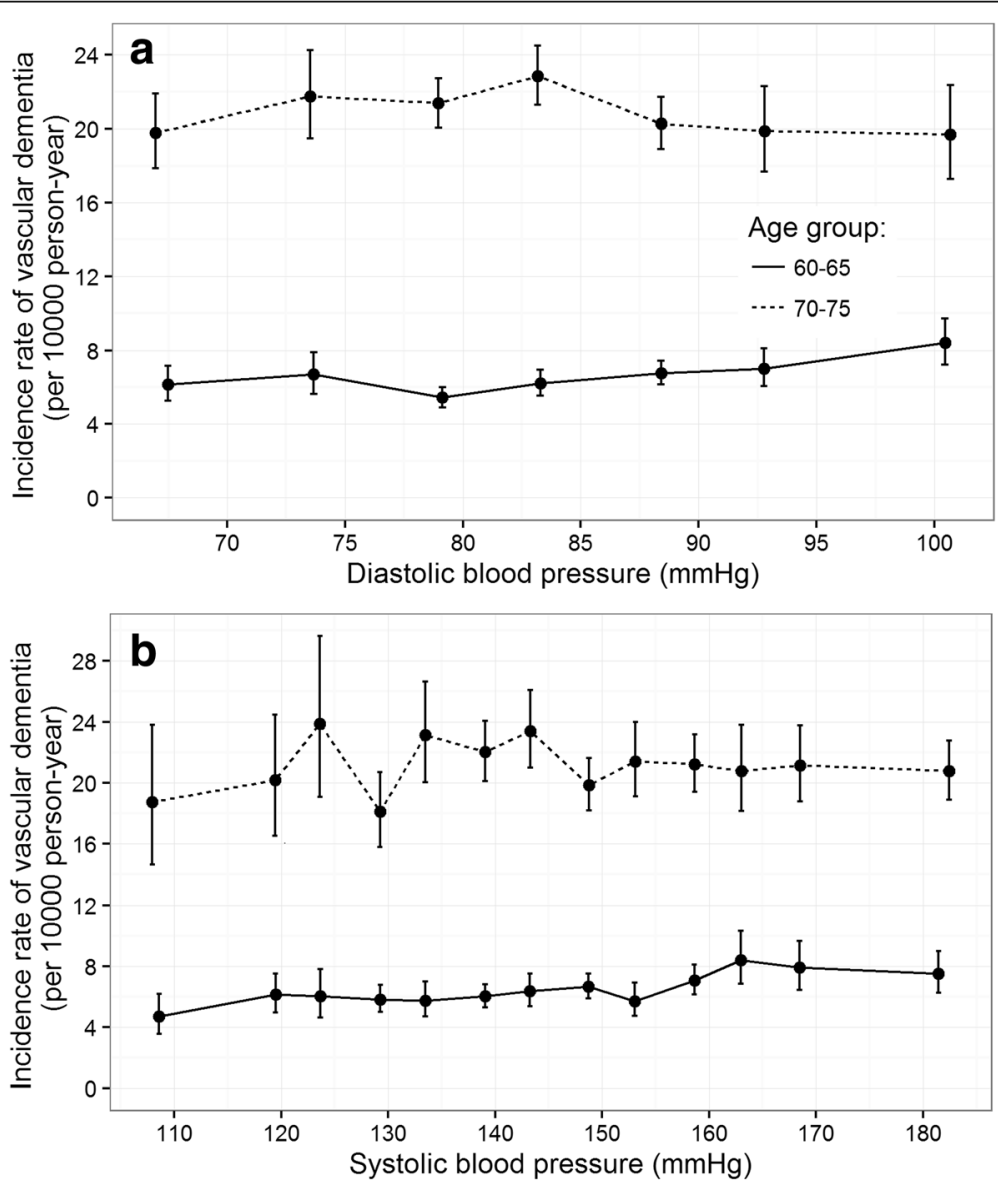

Fig. 1 Age and sex-standardized rate of vascular dementia per 10,000 person-years by (a) diastolic and (b) systolic blood pressure. Blood pressure were categorized based on the $5 \mathrm{mmHg}$ interval 
combining results obtained from each of them. Models were separately developed for 10 complete datasets and the results were combined for the final inference [24].

\section{Results}

Baseline demographics and clinical characteristics

The clinical characteristics of both study cohorts are summarized in Table III and IV in the online-only supplements. In total, there were 265,897 patients $(65.1 \%$ with stage 1 and 2 hypertension) in the age 60-65 cohort and 211,116 patients (76.3\% with stage 1 and 2 hypertension) in the age $70-75$ cohort. The proportion of patients with at least $2 \mathrm{BP}$ measurements within a 2 year period was $58.4 \%$ of in the age $60-65$ cohort and $64.4 \%$ in the age $70-75$ cohort. For the age $60-65$ cohort, $46.7 \%$ were male and $2.5 \%$ and $6.7 \%$ had a history of stroke and diabetes, respectively; for the age $70-75$ cohort, $43 \%$ were male and 2.8 and $7.7 \%$ had a history of stroke and diabetes, respectively.

\section{Incidence rate of vascular dementia}

We explored the association of systolic and diastolic blood pressure with vascular dementia by estimating the age and sex standardized incidence rate of vascular dementia for each category of SBP and DBP (Fig. 1). There was no clear trend between $\mathrm{VaD}$ and systolic and diastolic blood pressure in the age 70-75 cohort. In the age 60-65 cohort, the incidence rate of $\mathrm{VaD}$ for individuals with systolic blood pressures below $140 \mathrm{mmHg}$ was 5.8 per 10,000 person-years, which was lower than individuals with systolic blood pressures above $160 \mathrm{mmHg}$ (7.8 per 10,000 person-years).

\section{Age 60-65 cohort}

The proportion of male patients decreased with higher BP levels (Table III). The proportion of current smokers decreased with higher BP levels while the proportion of individuals with obesity increased. Individuals with normal and stage 2 hypertension have slightly more missing values than the other two groups. The proportion of patients with a history of diabetes, stroke and TIA increased at higher BP levels while the proportion of patients with a history of depression, head injury, and Parkinson' disease decreased at higher BP levels. Around $15 \%$ to $22 \%$ of individuals died, with the highest proportion of death for those with stage 2 hypertension. The mean follow up time was 11.0 years (standard deviation (SD): 4.97).

Figure 2 (a) shows the cumulative incidence of $\mathrm{VaD}$ for the age 60-65 cohort after accounting for the competing risk of death. At 20 years of follow-up, the cumulative incidence of $\mathrm{VaD}$ in patients with stage 2 hypertension was
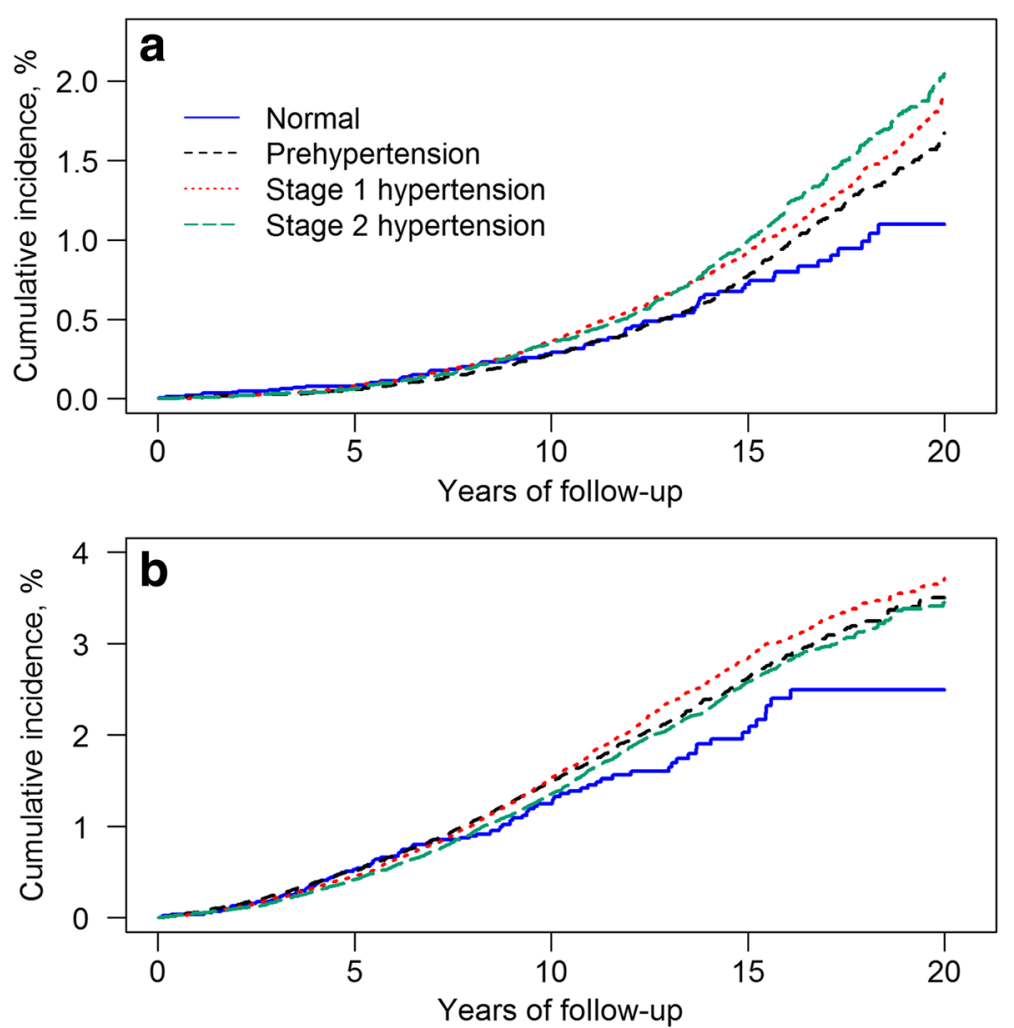

Fig. 2 Comparison of the cumulative incidence of vascular dementia for individuals with normal, prehypertension, stage 1 and 2 hypertension in the age 60-65 (a) and age 70-75cohorts (b), adjusting for the competing risk of death 
approximately $2 \%$ while the cumulative incidence of $\mathrm{VaD}$ in patients with normal blood pressure was $1 \%$. The difference in the cumulative incidence of $\mathrm{VaD}$ for patients with different BP levels rose after the 10 years of follow-up. For the untreated group without use of antihypertensive drugs, after adjusting for age and sex, the risk of $\mathrm{VaD}$ increased with higher BP levels, with a hazard ratio (HR) of 1.50 (95\% confidence interval: 1.02, 2.20) for prehypertension, $1.84(1.26,2.68)$ for stage 1 hypertension, and 2.09 (1.41, 3.10) for stage 2 hypertension (Table 1). The increased risk of $\mathrm{VaD}$ with increasing of $\mathrm{BP}$ levels remained significant after adjusting for potential confounding factors (age, sex, BMI, smoking status, and history of diabetes, stroke, head injury, depression and Parkinson's disease). After multiple imputation, the HRs for $\mathrm{VaD}$ increased slightly in each $\mathrm{BP}$ levels compared to age and sex adjusted HRs. For the treated group, there was no increasing risk of $\mathrm{VaD}$ with increasing of BP levels. For each BP level, our data showed that the treated group had higher crude incidence of $\mathrm{VaD}$ than untreated group (Table 1). PP levels were not identified as a risk predictor for $\mathrm{VaD}$ in both untreated and treated group (Table 2). This pattern was consistent after adjusting the other confounding factors and imputing missing values (Table 2). However, after stratified by $\mathrm{BP}, \mathrm{PP}$ was still not associated with $\mathrm{VaD}$ except for the untreated group with stage 1 hypertension (Table 3 ). Hazard ratios for the two groups with $\mathrm{PP}>60 \mathrm{mmHg}$ were inconsistent before and after imputing missing value. Additional file 1: Table S3 indicated that individuals with normal and stage 2 hypertension had more missing values in smoking status and BMI categories than the other two groups. Our further analyses on untreated patients with stage 1 hypertension showed that the individuals with PP levels of $\leq 50 \mathrm{mmHg}$ and $\mathrm{PP}>70 \mathrm{mmHg}$ had more missing values than the other two groups.

\section{Age 70-75 cohort}

The proportion of male patients decreased with higher BP levels, ranging from 55.2 to $37.1 \%$ (Table IV). Similar to the late midlife cohort, the proportion of patients with obesity increased at higher BP levels and the proportion of patients with a history of depression, head injury, and Parkinson's disease decreased at higher BP levels. In contrast to the age 60-65 cohort, the proportion of patients with a history of stroke, TIA, and

Table 1 Association between blood pressure levels and vascular dementia in age 60-65 and 70-75 cohorts

\begin{tabular}{|c|c|c|c|c|c|c|c|c|c|}
\hline Blood pressure levels & N & Death, \% & $\mathrm{VaD}, \%$ & Hazard ratio ${ }^{a}(95 \% \mathrm{Cl})$ & $P$ value & Hazard ratio ${ }^{b}(95 \% \mathrm{Cl})$ & $P$ value & Hazard ratio $^{\complement}(95 \% \mathrm{Cl})$ & $P$ value \\
\hline \multicolumn{10}{|c|}{ Age 60-65 cohort - untreated with antihypertensive drug } \\
\hline Normal & 10,335 & 13.49 & 0.39 & 1.00 (reference) & & & & 1.00 (reference) & \\
\hline Prehypertension & 56,231 & 13.24 & 0.55 & $1.50(1.02,2.20)$ & 0.04 & $1.25(0.88,1.77)$ & 0.21 & $1.53(1.04,2.25)$ & 0.03 \\
\hline Stage 1 hypertension & 71,191 & 15.73 & 0.66 & $1.84(1.26,2.68)$ & 0.002 & $1.46(1.03,2.05)$ & 0.032 & $1.90(1.30,2.78)$ & 0.001 \\
\hline Stage 2 hypertension & 29,197 & 20.86 & 0.83 & $2.09(1.41,3.10)$ & $<0.001$ & $1.49(1.04,2.13)$ & 0.03 & $2.19(1.48,3.26)$ & $<0.001$ \\
\hline \multicolumn{10}{|c|}{ Age 60-65 cohort - treated with antihypertensive drug } \\
\hline Normal & 3344 & 25.60 & 0.84 & 1.00 (reference) & & 1.00 (reference) & & 1.00 (reference) & \\
\hline Prehypertension & 22,707 & 18.64 & 0.66 & $0.92(0.56,1.52)$ & 0.75 & $0.90(0.58,1.40)$ & 0.64 & $0.91(0.55,1.50)$ & 0.71 \\
\hline Stage 1 hypertension & 47,227 & 17.50 & 0.75 & $1.05(0.65,1.69)$ & 0.84 & $0.97(0.63,1.48)$ & 0.88 & $1.04(0.65,1.68)$ & 0.86 \\
\hline Stage 2 hypertension & 25,665 & 22.70 & 0.86 & $1.07(0.65,1.75)$ & 0.79 & $0.92(0.59,1.42)$ & 0.70 & $1.08(0.66,1.77)$ & 0.76 \\
\hline \multicolumn{10}{|c|}{ Age $70-75$ cohort - untreated with antihypertensive drug } \\
\hline Normal & 3269 & 32.82 & 1.50 & 1.00 (reference) & & 1.00 (reference) & & 1.00 (reference) & \\
\hline Prehypertension & 24,080 & 30.32 & 1.65 & $1.18(0.82,1.72)$ & 0.37 & $1.07(0.76,1.52)$ & 0.69 & $1.19(0.82,1.72)$ & 0.37 \\
\hline Stage 1 hypertension & 46,194 & 31.58 & 1.72 & $1.18(0.82,1.69)$ & 0.38 & $1.13(0.81,1.59)$ & 0.47 & $1.18(0.82,1.70)$ & 0.37 \\
\hline Stage 2 hypertension & 30,874 & 36.97 & 1.72 & $1.12(0.77,1.62)$ & 0.55 & $1.09(0.77,1.53)$ & 0.64 & $1.14(0.79,1.65)$ & 0.49 \\
\hline \multicolumn{10}{|c|}{ Age 70-75 cohort - treated with antihypertensive drug } \\
\hline Normal & 2854 & 46.74 & 1.51 & 1.00 (reference) & & 1.00 (reference) & & 1.00 (reference) & \\
\hline Prehypertension & 20,032 & 36.74 & 1.81 & $1.49(0.94,2.35)$ & 0.09 & $1.10(0.78,1.54)$ & 0.60 & $1.50(0.95,2.37)$ & 0.085 \\
\hline Stage 1 hypertension & 48,593 & 33.30 & 1.91 & $1.76(1.12,2.74)$ & 0.013 & $1.17(0.84,1.63)$ & 0.37 & $1.78(1.14,2.79)$ & 0.011 \\
\hline Stage 2 hypertension & 36,220 & 38.65 & 1.89 & $1.56(1.00,2.45)$ & 0.052 & $1.11(0.79,1.54)$ & 0.56 & $1.60(1.02,2.51)$ & 0.041 \\
\hline
\end{tabular}

${ }^{\mathrm{b}}$ Adjusted for sex (female $=1$ ), age, body mass index, smoking status, history of diabetes, stroke, transient ischemic attack, head injury and Parkinson' disease while excluding any individuals with missing values

'Adjusted for sex (female $=1$ ), age, body mass index, smoking status, history of diabetes, stroke, transient ischemic attack, head injury and Parkinson' disease with missing values imputed by multiple imputation method 
Table 2 Association between pulse pressure levels and vascular dementia in age 60-65 and 70-75 cohorts

\begin{tabular}{|c|c|c|c|c|c|c|c|c|c|}
\hline Pulse pressure (PP) (mmHg) & N & Death, \% & $\mathrm{VaD}, \%$ & Hazard ratio ${ }^{\mathrm{a}}(95 \% \mathrm{Cl})$ & $P$ value & Hazard ratio $^{\mathrm{b}}(95 \% \mathrm{Cl})$ & $P$ value & Hazard ratio ${ }^{c}(95 \% \mathrm{Cl})$ & $P$ value \\
\hline \multicolumn{10}{|c|}{ Age 60-65 cohort - untreated with antihypertensive drug } \\
\hline$P P \leq 50$ & 51,721 & 14.17 & 0.55 & 1.00 (reference) & & 1.00 (reference) & & 1.00 (reference) & \\
\hline $50<P P \leq 60$ & 49,975 & 14.49 & 0.64 & $1.11(0.93,1.33)$ & 0.24 & $1.72(0.98,1.40)$ & 0.77 & $1.11(0.93,1.34)$ & 0.24 \\
\hline $60<\mathrm{PP} \leq 70$ & 37,159 & 16.02 & 0.68 & $1.18(0.97,1.43)$ & 0.10 & $1.19(0.98,1.44)$ & 0.74 & $1.18(0.97,1.43)$ & 0.1 \\
\hline $\mathrm{PP}>70$ & 28,099 & 19.97 & 0.74 & $1.15(0.93,1.42)$ & 0.19 & $1.19(0.97,1.45)$ & 0.89 & $1.15(0.94,1.42)$ & 0.18 \\
\hline \multicolumn{10}{|c|}{ Age 60-65 cohort - treated with antihypertensive drug } \\
\hline$P P \leq 50$ & 15,556 & 21.43 & 0.71 & 1.00 (reference) & & 1.00 (reference) & & 1.00 (reference) & \\
\hline $50<\mathrm{PP} \leq 60$ & 26,748 & 17.83 & 0.73 & $1.03(0.78,1.35)$ & 0.86 & $1.03(0.81,1.33)$ & 0.80 & $1.02(0.77,1.33)$ & 0.91 \\
\hline $60<\mathrm{PP} \leq 70$ & 28,574 & 17.66 & 0.79 & $1.15(0.88,1.49)$ & 0.31 & $1.11(0.87,1.41)$ & 0.41 & $1.13(0.87,1.47)$ & 0.36 \\
\hline $\mathrm{PP}>70$ & 28,065 & 21.48 & 0.78 & $1.03(0.79,1.36)$ & 0.81 & $0.98(0.76,1.26)$ & 0.87 & $1.02(0.78,1.34)$ & 0.88 \\
\hline \multicolumn{10}{|c|}{ Age $70-75$ cohort - untreated with antihypertensive drug } \\
\hline$P P \leq 50$ & 18,081 & 32.91 & 1.54 & 1.00 (reference) & & 1.00 (reference) & & 1.00 (reference) & \\
\hline $50<\mathrm{PP} \leq 60$ & 24,951 & 31.28 & 1.64 & $1.06(0.88,1.28)$ & 0.51 & $1.12(0.93,1.34)$ & 0.23 & $1.06(0.88,1.27)$ & 0.57 \\
\hline $60<P P \leq 70$ & 27,114 & 31.78 & 1.74 & $1.08(0.90,1.29)$ & 0.43 & $1.21(1.12,1.44)$ & 0.031 & $1.07(0.89,1.28)$ & 0.48 \\
\hline $\mathrm{PP}>70$ & 34,271 & 35.02 & 1.79 & $1.08(0.91,1.29)$ & 0.38 & $1.15(0.94,1.37)$ & 0.10 & $1.08(0.91,1.29)$ & 0.37 \\
\hline \multicolumn{10}{|c|}{ Age 70-75 cohort - treated with antihypertensive drug } \\
\hline$P P \leq 50$ & 10,268 & 42.75 & 1.76 & 1.00 (reference) & & 1.00 (reference) & & 1.00 (reference) & \\
\hline $50<\mathrm{PP} \leq 60$ & 20,576 & 35.92 & 1.82 & $1.27(1.00,1.61)$ & 0.046 & $1.00(0.82,1.22)$ & 0.98 & $1.27(1.00,1.60)$ & 0.05 \\
\hline $60<\mathrm{PP} \leq 70$ & 29,672 & 33.86 & 1.96 & $1.39(1.11,1.73)$ & 0.004 & $1.07(0.89,1.28)$ & 0.50 & $1.38(1.10,1.73)$ & 0.005 \\
\hline $\mathrm{PP}>70$ & 47,183 & 36.13 & 1.86 & $1.17(0.94,1.46)$ & 0.15 & $0.97(0.81,1.16)$ & 0.73 & $1.18(0.94,1.46)$ & 0.15 \\
\hline
\end{tabular}

VaD: Vascular dementia; Cl: Confidence interval

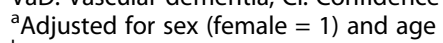

${ }^{\text {b} A d j u s t e d ~ f o r ~ s e x ~(f e m a l e ~}=1$ ), age, body mass index, smoking status, history of diabetes, stroke, transient ischemic attack, head injury and Parkinson' disease while excluding any individuals with missing values

'Adjusted for sex (female = 1), age, body mass index, smoking status, history of diabetes, stroke, transient ischemic attack, head injury and Parkinson'

disease with missing values imputed by multiple imputation method

diabetes decreased at higher BP levels. During follow-up, 32 to $39 \%$ of individuals died, with highest proportion of death in those with stage 1 hypertension. The mean follow-up time was 8.84 years (SD: 4.55).

Figure 2 (b) shows the cumulative incidence curves of $\mathrm{VaD}$ for the late life cohort after accounting for the competing risk of death. At 20 years of follow up, the cumulative incidence of $\mathrm{VaD}$ in patients with stage 1 and 2 hypertension was $3.3 \%$, while the cumulative incidence of $\mathrm{VaD}$ in patients with normal blood pressure was $2.4 \%$. The difference in the cumulative incidence of $\mathrm{VaD}$ for patients with different BP levels rose after 10 years of follow-up. Similar with the 60-65 cohort, the individuals in treated hypertension group had higher incidence of $\mathrm{VaD}$ than those in untreated group (Table 1). For the untreated group, there was no statistically significant association between the risk of $\mathrm{VaD}$ and $\mathrm{BP}$ levels (Table 1). For the treated group, the association was observed between $\mathrm{BP}$ and $\mathrm{VaD}$ for stage 1 and 2 hypertension patients after adjusting for potential confounding factors and with the imputed missing values. This association was no longer significant after excluding individuals with any missing values. Similar results were observed for analysis on PP levels (Table 2). The analyses stratified by BP levels indicated that PP level is not an independent risk factor for $\mathrm{VaD}$ (Table 4). Similar with the cohort aged 60-65 years, there are more missing values in smoking status and BMI categories in individuals with normal and stage 2 hypertension than the other two groups (Additional file 1: Table S4).

\section{Discussion}

In this study, there is an increasing risk of $\mathrm{VaD}$ with increasing levels in the age 60-65 cohort without antihypertensive drug, while such an association was not observed in the age 70-75 cohort. Therefore, optimal control of late midlife BP levels and prescription of antihypertensive drugs may be important to reduce the risk of $\mathrm{VaD}$. Further research is still needed to clarify the role of late-life high blood pressure on the prognosis of $\mathrm{VaD}$, especially for patients aged 70 and above.

Several studies that have previously examined the association between $\mathrm{VaD}$ and midlife $\mathrm{BP}$ levels reached similar conclusions. The Hisayama study found that subjects with prehypertension, stage 1 , and stage 2 hypertension in midlife (around 58 years) had higher risk of $\mathrm{VaD}$ after adjusting for potential risk factors [5]. The Honolulu Asia Aging Study recommended lowering 
Table 3 Association between Pulse pressure levels and vascular dementia stratified by blood pressure levels in age 60-65 cohort

\begin{tabular}{|c|c|c|c|c|c|c|c|c|c|}
\hline Pulse pressure (PP) (mmHg) & N & Death, \% & $\mathrm{VaD}, \%$ & Hazard ratio $^{\mathrm{a}}(95 \% \mathrm{Cl})$ & $P$ value & Hazard ratio ${ }^{\mathrm{b}}(95 \% \mathrm{Cl})$ & $P$ value & Hazard ratio ${ }^{c}(95 \% \mathrm{Cl})$ & $P$ value \\
\hline \multicolumn{10}{|c|}{ Age 60-65 cohort - untreated with antihypertensive drug } \\
\hline \multicolumn{10}{|l|}{ Prehypertension } \\
\hline$P P \leq 50$ & 32,434 & 13.56 & 0.52 & 1.00 (reference) & & 1.00 (reference) & & 1.00 (reference) & \\
\hline $50<\mathrm{PP} \leq 60$ & 20,007 & 12.60 & 0.59 & $1.01(0.77,1.33)$ & 0.95 & $1.14(0.88,1.48)$ & 0.32 & $0.99(0.75,1.30)$ & 0.93 \\
\hline $60<\mathrm{PP} \leq 70$ & 3503 & 13.79 & 0.51 & $0.92(0.53,1.60)$ & 0.77 & $1.07(0.64,1.80)$ & 0.79 & $0.88(0.51,1.53)$ & 0.65 \\
\hline $\mathrm{PP}>70$ & 217 & 15.21 & 0.92 & $2.15(0.53,8.71)$ & 0.28 & $2.63(0.64,1.08)$ & 0.18 & $2.00(0.49,8.15)$ & 0.33 \\
\hline \multicolumn{10}{|l|}{ Stage 1 hypertension } \\
\hline$P P \leq 50$ & 8330 & 16.47 & 0.79 & 1.00 (reference) & & 1.00 (reference) & & 1.00 (reference) & \\
\hline $50<\mathrm{PP} \leq 60$ & 27,993 & 15.63 & 0.68 & $0.79(0.58,1.07)$ & 0.13 & $1.02(0.74,1.40)$ & 0.93 & $0.78(0.57,1.06)$ & 0.11 \\
\hline $60<\mathrm{PP} \leq 70$ & 26,983 & 15.28 & 0.65 & $0.70(0.51,0.96)$ & 0.028 & $0.97(0.70,1.34)$ & 0.84 & $0.68(0.49,0.94)$ & 0.018 \\
\hline $\mathrm{PP}>70$ & 7885 & 16.89 & 0.55 & $0.59(0.38,0.91)$ & 0.016 & $0.95(0.62,1.44)$ & 0.80 & $0.56(0.36,0.87)$ & 0.009 \\
\hline \multicolumn{10}{|l|}{ Stage 2 hypertension } \\
\hline$P P \leq 50$ & 1162 & 19.88 & 0.86 & 1.00 (reference) & & 1.00 (reference) & & 1.00 (reference) & \\
\hline $50<\mathrm{PP} \leq 60$ & 1393 & 19.45 & 0.72 & $1.10(0.38,3.15)$ & 0.86 & $0.62(0.23,1.67)$ & 0.35 & $1.09(0.38,3.14)$ & 0.87 \\
\hline $60<\mathrm{PP} \leq 70$ & 6647 & 20.19 & 0.92 & $1.41(0.61,3.28)$ & 0.42 & $0.85(0.42,1.73)$ & 0.65 & $1.42(0.61,3.29)$ & 0.42 \\
\hline $\mathrm{PP}>70$ & 19,995 & 21.24 & 0.81 & $1.02(0.45,2.31)$ & 0.96 & $0.80(0.41,1.57)$ & 0.52 & $1.03(0.46,2.34)$ & 0.94 \\
\hline \multicolumn{10}{|c|}{ Age 60-65 cohort - treated with antihypertensive drug } \\
\hline \multicolumn{10}{|l|}{ Prehypertension } \\
\hline$P P \leq 50$ & 9363 & 20.06 & 0.68 & 1.00 (reference) & & 1.00 (reference) & & 1.00 (reference) & \\
\hline $50<\mathrm{PP} \leq 60$ & 11,113 & 17.39 & 0.62 & $0.84(0.57,1.23)$ & 0.37 & $0.97(0.68,1.39)$ & 0.87 & $0.83(0.56,1.22)$ & 0.33 \\
\hline $60<\mathrm{PP} \leq 70$ & 2131 & 19.05 & 0.80 & $1.19(0.66,2.15)$ & 0.57 & $1.41(0.81,2.47)$ & 0.23 & $1.13(0.61,2.10)$ & 0.70 \\
\hline $\mathrm{PP}>70$ & 100 & 17.00 & 0.00 & N/A & N/A & N/A & N/A & N/A & N/A \\
\hline \multicolumn{10}{|l|}{ Stage 1 hypertension } \\
\hline$P P \leq 50$ & 2648 & 20.70 & 0.72 & 1.00 (reference) & & 1.00 (reference) & & 1.00 (reference) & \\
\hline $50<\mathrm{PP} \leq 60$ & 14,601 & 17.81 & 0.78 & $1.39(0.74,2.62)$ & 0.30 & $1.11(0.65,1.88)$ & 0.71 & $1.38(0.73,2.59)$ & 0.32 \\
\hline $60<\mathrm{PP} \leq 70$ & 21,800 & 16.64 & 0.75 & $1.32(0.71,2.47)$ & 0.38 & $1.08(0.64,1.81)$ & 0.78 & $1.29(0.69,2.40)$ & 0.43 \\
\hline $\mathrm{PP}>70$ & 8178 & 18.22 & 0.69 & $1.31(0.67,2.55)$ & 0.43 & $1.01(0.57,1.79)$ & 0.97 & $1.24(0.63,2.42)$ & 0.53 \\
\hline \multicolumn{10}{|l|}{ Stage 2 hypertension } \\
\hline$P P \leq 50$ & 405 & 26.67 & 0.49 & 1.00 (reference) & & 1.00 (reference) & & 1.00 (reference) & \\
\hline $50<\mathrm{PP} \leq 60$ & 835 & 21.92 & 1.08 & $1.68(0.35,8.14)$ & 0.52 & $1.78(0.37,8.50)$ & 0.47 & $1.61(0.33,7.81)$ & 0.56 \\
\hline $60<\mathrm{PP} \leq 70$ & 4638 & 21.84 & 1.01 & $1.46(0.35,6.17)$ & 0.60 & $1.49(0.35,6.26)$ & 0.59 & $1.41(0.33,5.93)$ & 0.64 \\
\hline $\mathrm{PP}>70$ & 19,787 & 22.85 & 0.83 & $1.09(0.26,4.51)$ & 0.90 & $1.29(0.31,5.33)$ & 0.73 & $1.02(0.25,4.24)$ & 0.98 \\
\hline
\end{tabular}

VaD: Vascular dementia; Cl: Confidence interval

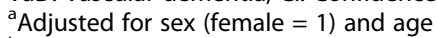

bAdjusted for sex (female = 1), age, body mass index, smoking status, history of diabetes, stroke, transient ischemic attack, head injury and Parkinson' disease while excluding any individuals with missing values

'Adjusted for sex (female $=1$ ), age, body mass index, smoking status, history of diabetes, stroke, transient ischemic attack, head injury and Parkinson' disease with missing values imputed by multiple imputation method

midlife (aged 45-68 years) systolic blood pressure as a public health strategy to reduce late-life dementia after demonstrating high of risk of $\mathrm{VaD}$ for patients with untreated hypertension [8]. High blood pressure at middle age implies a long-term cumulative effect, which leads to increased severity of atherosclerosis and more vascular comorbidities in late life [7]. Patients with high blood pressure in midlife were at increased risk of $\mathrm{VaD}$, regardless of late-life BP levels, [5] likely as midlife hypertension leads to damage that becomes irreversible in the late life. Our findings highlight the potential importance of blood pressure control in the midlife period.

Trials of antihypertensive therapy have not yet clarified the impact of blood pressure lowering on vascular dementia. Our study identified the increasing risk of $\mathrm{VaD}$ with an increase of $\mathrm{BP}$ levels for the individuals without the use of antihypertensive drugs, while there was no association between $\mathrm{BP}$ levels and $\mathrm{VaD}$ in the treated individuals. A recent meta-analysis of trials and cohort studies showed promising findings that diuretic- 
Table 4 Association between pulse pressure levels and vascular dementia stratified by blood pressure levels in age 70-75 cohort

\begin{tabular}{|c|c|c|c|c|c|c|c|c|c|}
\hline Pulse pressure (PP) (mmHg) & N & Death, \% & $\mathrm{VaD}, \%$ & Hazard ratio $^{\mathrm{a}}(95 \% \mathrm{Cl})$ & $P$ value & Hazard ratio ${ }^{\mathrm{b}}(95 \% \mathrm{Cl})$ & $P$ value & Hazard ratio ${ }^{c}(95 \% \mathrm{Cl})$ & $P$ value \\
\hline \multicolumn{10}{|c|}{ Age 70-75 cohort - untreated with antihypertensive drug } \\
\hline \multicolumn{10}{|l|}{ Prehypertension } \\
\hline$P P \leq 50$ & 11,244 & 31.56 & 1.51 & 1.00 (reference) & & 1.00 (reference) & & 1.00 (reference) & \\
\hline $50<\mathrm{PP} \leq 60$ & 9872 & 29.55 & 1.81 & $1.12(0.86,1.45)$ & 0.41 & $1.20(0.93,1.54)$ & 0.16 & $1.09(0.84,1.41)$ & 0.54 \\
\hline $60<\mathrm{PP} \leq 70$ & 2669 & 27.69 & 1.72 & $1.34(0.93,1.93)$ & 0.12 & $1.20(0.83,1.73)$ & 0.34 & $1.30(0.90,1.88)$ & 0.16 \\
\hline $70<\mathrm{PP}$ & 295 & 32.54 & 1.02 & $0.60(0.15,2.44)$ & 0.48 & $0.61(0.15,2.46)$ & 0.49 & $0.59(0.15,2.40)$ & 0.46 \\
\hline \multicolumn{10}{|l|}{ Stage 1 hypertension } \\
\hline$P P \leq 50$ & 3312 & 36.75 & 1.72 & 1.00 (reference) & & 1.00 (reference) & & 1.00 (reference) & \\
\hline $50<\mathrm{PP} \leq 60$ & 14,051 & 32.02 & 1.54 & $0.91(0.64,1.30)$ & 0.61 & $1.01(0.71,1.44)$ & 0.95 & $0.90(0.63,1.28)$ & 0.55 \\
\hline $60<\mathrm{PP} \leq 70$ & 19,583 & 30.94 & 1.79 & $0.97(0.69,1.37)$ & 0.85 & $1.21(0.86,1.70)$ & 0.28 & $0.95(0.67,1.34)$ & 0.76 \\
\hline $70<\mathrm{PP}$ & 9248 & 30.43 & 1.83 & $0.99(0.68,1.44)$ & 0.97 & $1.13(0.78,1.64)$ & 0.52 & $0.97(0.67,1.41)$ & 0.88 \\
\hline \multicolumn{10}{|l|}{ Stage 2 hypertension } \\
\hline$P P \leq 50$ & 556 & 38.85 & 0.90 & 1.00 (reference) & & 1.00 (reference) & & 1.00 (reference) & \\
\hline $50<\mathrm{PP} \leq 60$ & 757 & 39.37 & 1.32 & $1.95(0.52,7.34)$ & 0.32 & $1.25(0.36,4.28)$ & 0.72 & $1.94(0.52,7.32)$ & 0.33 \\
\hline $60<\mathrm{PP} \leq 70$ & 4836 & 37.39 & 1.53 & $1.64(0.51,5.27)$ & 0.41 & $1.40(0.51,3.86)$ & 0.52 & $1.67(0.52,5.36)$ & 0.39 \\
\hline $70<\mathrm{PP}$ & 24,725 & 36.77 & 1.78 & $2.08(0.67,6.47)$ & 0.21 & $1.59(0.59,4.27)$ & 0.36 & $2.10(0.68,6.53)$ & 0.20 \\
\hline \multicolumn{10}{|c|}{ Age 70-75 cohort - treated with antihypertensive drug } \\
\hline \multicolumn{10}{|l|}{ Prehypertension } \\
\hline$P P \leq 50$ & 5994 & 40.19 & 1.84 & 1.00 (reference) & & 1.00 (reference) & & 1.00 (reference) & \\
\hline $50<\mathrm{PP} \leq 60$ & 9948 & 35.27 & 1.78 & $1.27(0.92,1.76)$ & 0.14 & $0.95(0.73,1.24)$ & 0.71 & $1.23(0.89,1.70)$ & 0.21 \\
\hline $60<\mathrm{PP} \leq 70$ & 3728 & 34.74 & 1.88 & $1.38(0.94,2.05)$ & 0.1 & $1.02(0.73,1.42)$ & 0.91 & $1.30(0.88,1.93)$ & 0.18 \\
\hline $70<\mathrm{PP}$ & 362 & 40.33 & 1.38 & $0.87(0.27,2.79)$ & 0.81 & $0.81(0.32,2.01)$ & 0.64 & $0.80(0.25,2.58)$ & 0.71 \\
\hline \multicolumn{10}{|l|}{ Stage 1 hypertension } \\
\hline$P P \leq 50$ & 1511 & 44.08 & 1.99 & 1.00 (reference) & & 1.00 (reference) & & 1.00 (reference) & \\
\hline $50<\mathrm{PP} \leq 60$ & 9789 & 36.02 & 1.87 & $0.88(0.56,1.38)$ & 0.57 & $0.82(0.54,1.23)$ & 0.33 & $0.87(0.55,1.36)$ & 0.53 \\
\hline $60<\mathrm{PP} \leq 70$ & 22,333 & 32.49 & 2.02 & $0.92(0.60,1.42)$ & 0.71 & $0.84(0.57,1.24)$ & 0.39 & $0.90(0.59,1.39)$ & 0.64 \\
\hline $70<\mathrm{PP}$ & 14,960 & 31.66 & 1.75 & $0.70(0.45,1.09)$ & 0.12 & $0.71(0.48,1.06)$ & 0.10 & $0.68(0.44,1.07)$ & 0.096 \\
\hline \multicolumn{10}{|l|}{ Stage 2 hypertension } \\
\hline$P P \leq 50$ & 291 & 47.08 & 1.72 & 1.00 (reference) & & 1.00 (reference) & & 1.00 (reference) & \\
\hline $50<\mathrm{PP} \leq 60$ & 480 & 43.96 & 1.67 & $0.76(0.17,3.39)$ & 0.72 & $1.17(0.30,4.54)$ & 0.82 & $0.77(0.17,3.42)$ & 0.73 \\
\hline $60<\mathrm{PP} \leq 70$ & 3588 & 41.44 & 1.67 & $0.90(0.28,2.91)$ & 0.86 & $1.01(0.31,3.23)$ & 0.99 & $0.90(0.28,2.92)$ & 0.86 \\
\hline $70<\mathrm{PP}$ & 31,861 & 38.18 & 1.92 & $1.04(0.34,3.24)$ & 0.94 & $1.12(0.36,3.48)$ & 0.85 & $1.05(0.34,3.25)$ & 0.94 \\
\hline
\end{tabular}

VaD Vascular dementia, $\mathrm{Cl}$ Confidence interval

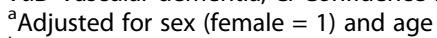

bAdjusted for sex (female = 1), age, body mass index, smoking status, history of diabetes, stroke, transient ischemic attack, head injury and Parkinson' disease while excluding any individuals with missing values

'Adjusted for sex (female = 1), age, body mass index, smoking status, history of diabetes, stroke, transient ischemic attack, head injury and Parkinson' disease with missing values imputed by multiple imputation method

based lowering of blood pressure prevents dementia [25]. Other trials and a meta-analysis of trials have produced inconsistent results, likely related to the trials being retrospectively designed, with weaker assessments of dementia and its components, and follow-up times that are too short [26-28]. Additional randomized controlled trials with more sensitive and specific tests for dementia and its components, as well as longer follow-up periods, may be needed to clarify the impact of hypertension on dementia.
However, given the strong evidence that antihypertensive therapy has beneficial effects on cardiovascular outcomes, most trial designs would be unethical to conduct. The recent SPRINT trial examining newer blood pressure targets is an exception and its results on dementia are anticipated [29].

Increases of PP in midlife is closely related to the increases of SBP. The associations between PP and VaD were not significant when stratified analyses at each BP level and treatment status were conducted. Therefore, 
PP was not independently associated with $\mathrm{VaD}$. This is consistent with results from the other study [30]. Pulse pressure may not be an adequate measure of arterial stiffness and pulsatile flow as pulse wave velocity has been shown to prevent cognitive decline better than measures of blood pressure [31].

After adjusting the competing risk of death and other risk factors, our study found no association between BP levels and risk of vascular dementia in the age 70-75 cohort. This could be due to several reasons. First, there is a graded increase in the risk of stroke with advancing age, [32] with a doubling in the stroke rate with each successive 10 years after age $55[33,34]$. Second, after acute stroke, patients with high blood pressure levels have higher mortality rate [35]. As a result, survivors of strokes are more likely to have normal blood pressure (as shown in Table II). Third, a decline of blood pressure happens in the pathogenesis of dementia [36]. This could weaken the association between high blood pressure levels and risk of vascular dementia in late-life. Fourth, competing risk of death is more significant in later life. There is a potential "floor effect" of death on the development of vascular dementia. In our study, $40 \%$ of patients in the late-life cohort died during follow-up. The patients were likely to die before the development and diagnosis of vascular dementia. To assess the true effects of vascular risk factor on the development of vascular dementia, it may be necessary to use brain autopsy and neuroimaging to identify dementia cases.

Clear association of late midlife high $\mathrm{BP}$ and $\mathrm{VaD}$ in untreated group supports the need to treat and control BPs for patients with late midlife hypertension. According to health surveys, around half of patients with hypertension do not have their blood pressure under control [37]. In our study, only 20 to $25 \%$ patients with stage 1 and 2 hypertension had a diagnosis of hypertension in EMR record. Patients with a code of hypertension diagnosis in EMR are more likely to receive treatments [38, 39]. Therefore, greater effort must be made for the early diagnosis and treatment of hypertension, especially in midlife.

Our study is a large, population-based cohort study, which enabled us to examine the association of vascular dementia related to late midlife and late life blood pressure. We also accounted for the competing risk of death and adjusted for several important risk factors for dementia. However, several limitations should be noted. First, selection bias might exist since we only included patients who had at least one blood pressure measurement before the ages of 65 and 75 . Around $40 \%$ of patients in the study cohorts had only a single measurement of blood pressure and this would have led to some degree of misclassification of blood pressure levels. Also, patients with hypertension requiring frequent visits may increase the reporting of dementia. Second, there are potential problems with misclassification or misdiagnosis of vascular dementia. This issue stems from difficulty with the clinical differentiation and classification of dementia subtypes; [40] there is inconsistency in applying commonly used classification systems for the dementia diagnoses. However, the diagnosis in EMR is closely relevant to routine clinical care and has shown good agreement with physician diagnosis and other data sources. Third, people with higher levels of blood pressure may be more apt to receive antihypertensive treatment than those with lower levels, reversing the relationship of hypertension to stroke and dementia. To alleviate this issue, we stratified the analysis using the drug use status. Lastly, missing or incomplete information on some risk factors could impact the validity of results. Our analysis showed inconsistency of results with and without imputing missing values in some subcategories. Some potential confounders were not recorded well in the database and subsequently excluded from the analysis. For example, exercise levels were only recorded in $22 \%$ of individuals in the study cohorts and were not included in the analysis.

\section{Conclusions}

In summary, our study indicates that high blood pressure between the ages of 60 and 65 is a significant risk factor for vascular dementia in an untreated late midlife cohort. Given the strength and consistency of this evidence, greater efforts should be made to diagnose hypertension early, and control blood pressure for hypertensive patients in the prevention to better prevent vascular dementia.

\section{Additional files}

Additional files 1: List of Read codes (Table S1) and antihypertensive drugs (Table S2), Clinical characteristics of study cohort with the age of 60 to 65 (Table S3) and 70 to 75 (Table S4). (DOCX 36 kb)

\section{Acknowledgements}

We thank the staff from Clinical Research Unit (CRU), Cumming School of Medicine for their technical support for this study.

\section{Funding}

This study was funded by the Pilot funding for vascular cognitive impairment research - Katthy Taylor Chair in Vascular Dementia, University of Calgary. EES is the Kathy Taylor Chair in Vascular Dementia. The sponsors/funders had no role in the design and conduct of the study; in the collection, analysis, and interpretation of the data; or in the preparation, review, or approval of the manuscript.

\section{Availability of data and materials}

The data that support the findings of this study are available from IMS Health Real World Evidence Solutions but restrictions apply to the availability of these data, which were used under license for the current study, and so are not publicly available.

\section{Authors' contributions}

MP, GC, KLT and NC conceived and designed the study. MP and GC carried out data collection and statistical analysis. GC, HQ, EES, PF, VH, NC participated in the study planning and interpreted the results. MP wrote the manuscript, and all authors (MP, GC, KLT, HQ, EES, PF, VH, and NC) contributed to manuscript critical appraisal and review. All authors reviewed and agreed on the final version of the manuscript. 


\section{Ethics approval and consent to participate}

This study was approved by The Conjoint Health Research Ethics Board (CHREB), University of Calgary. All the records were anonymized.

\section{Consent for publication}

Not Applicable.

\section{Competing interests}

The authors declare that they have no competing interests.

\section{Publisher's Note}

Springer Nature remains neutral with regard to jurisdictional claims in published maps and institutional affiliations.

\begin{abstract}
Author details
${ }^{1}$ Department of Community Health Sciences, University of Calgary, Calgary T2N 1N4, Canada. ${ }^{2}$ Alberta Health Services, Calgary T2N 4L7, Canada. ${ }^{3}$ Cumming School of Medicine, University of Calgary, Calgary T2N 1N4, Canada. ${ }^{4}$ Department of Clinical Neurosciences, University of Calgary, Calgary T2N 1N4, Canada. ${ }^{5}$ Department of Clinical Neurological Sciences, London Health Sciences Centre, Western University, London, ON N6A 5A5, Canada. ${ }^{6}$ Department of Medicine, Physiology and Pharmacology and Community Health Sciences, O'Brien Institute for Public Health and Libin Cardiovascular Institute of Alberta, University of Calgary, Calgary, AB T2N 1N4, Canada.
\end{abstract}

Received: 15 March 2017 Accepted: 19 October 2017

Published online: 27 October 2017

\section{References}

1. Prince M, Bryce R, Albanese E, Wimo A, Ribeiro W, Ferri CP. The global prevalence of dementia: a systematic review and metaanalysis. Alzheimers Dement. 2013;9:63-75.

2. Kearney PM, Whelton M, Reynolds K, Muntner P, Whelton PK, He J. Global burden of hypertension: analysis of worldwide data. Lancet. 2005;365:217-23.

3. Pohjasvaara T, Mäntylä R, Ylikoski R, Kaste M, Erkinjuntti T. Comparison of different clinical criteria (DSM-III, ADDTC, ICD-10, NINDS-AIREN, DSM-IV) for the diagnosis of vascular dementia. National Institute of Neurological Disorders and Stroke-Association Internationale pour la Recherche et I'Enseignement en neurosciences. Stroke. 2000;31:2952-7.

4. Mozaffarian D, Benjamin EJ, Go AS, Arnett DK, Blaha MJ, Cushman M, de Ferranti S, Despres JP, Fullerton HJ, Howard VJ, Huffman MD, Judd SE, Kissela BM, Lackland DT, Lichtman JH, Lisabeth LD, Liu S, Mackey RH, Matchar DB, DK MG, Mohler ER 3rd, Moy CS, Muntner P, Mussolino ME, Nasir K, Neumar RW, Nichol G, Palaniappan L, Pandey DK, Reeves MJ, Rodriguez CJ, Sorlie PD, Stein J, Towfighi A, Turan TN, Virani SS, Willey JZ, Woo D, Yeh RW, Turner MB. On behalf of the American Heart Association statistics Committeee and stroke statistics subcommittee. Heart disease and stroke statistics - 2015 update a report from the American Heart Association. Circulation. 2015;131:E29-E322.

5. Ninomiya T, Ohara T, Hirakawa Y, Yoshida D, Doi Y, Hata J, Kanba S, Iwaki T, Kiyohara Y. Midlife and late-life blood pressure and dementia in Japanese elderly: the Hisayama study. Hypertension. 2011;58:22-8.

6. Kennelly SP, Lawlor BA, Kenny RA. Blood pressure and dementia - a comprehensive review. Ther Adv Neurol Disord. 2009;2:241-60.

7. Qiu C, Winblad B, Fratiglioni L. The age-dependent relation of blood pressure to cognitive function and dementia. Lancet Neurol. 2005:4:487-99.

8. Launer LJ, Hughes T, Yu BB, Masaki K, Petrovitch H, Ross GW, White LR. Lowering midlife levels of systolic blood pressure as a public health strategy to reduce late-life dementia perspective from the Honolulu heart program/ Honolulu Asia aging study. Hypertension. 2010;55:1352-9.

9. Katzman R, Aronson M, Fuld P, Kawas C, Brown T, Morgenstern H, Frishman W, Gidez L, Eder H, Ooi WL. Development of dementing illnesses in an 80year-old volunteer cohort. Ann Neurol. 1989;25:317-24.

10. Ruitenberg A, Skoog I, Ott A, Aevarsson O, Witteman JC, Lernfelt B, van Harskamp F, Hofman A, Breteler MM. Blood pressure and risk of dementia: results from the Rotterdam study and the Gothenburg H-70 study. Dement Geriatr Cogn Disord 2001;12:33-39.

11. Mitchell GF, Vasan RS, Keyes MJ, Parise H, Wang TJ, Larson MG, D'Agostino RB, Kannel WB, Levy D, Benjamin EJ. Pulse pressure and risk of new-onset atrial fibrillation. JAMA. 2007;297:709-15.
12. Peng M, Chen G, Kaplan GG, Lix LM, Drummond N, Lucyk K, Garies S, Lowerison M, Weibe S, Quan $\mathrm{H}$. Methods of defining hypertension in electronic medical records: validation against national survey data. J Public Health. 2015:38:e392-9.

13. Blak BT, Thompson M, Dattani H, Bourke A. Generalisability of the health improvement network (THIN) database: demographics, chronic disease prevalence and mortality rates. Inform Prim Care. 2011;19:251-5.

14. Chisholm J. The read clinical classification. BMJ. 1990;300:1092.

15. Chobanian AV, Bakris GL, Black HR, Cushman WC, Green LA, Izzo JL, Jr., Jones DW, Materson BJ, Oparil S, Wright JT, Roccella EJ. and the National High Blood Pressure Education Program Coordinating Committee. The seventh report of the joint National Committee on prevention, detection, evaluation, and treatment of high blood pressure the JNC 7 report. Hypertension. 2003;42:1206-1252.

16. Rait G, Walters K, Bottomley C, Petersen I, lliffe S, Nazareth I. Sunvival of people with clinical diagnosis of dementia in primary care: cohort study. BMJ. 2010;341:C3584.

17. Walters K, Hardoon S, Petersen I, lliffe S, Omar RZ, Nazareth I, Rait G. Predicting dementia risk in primary care: development and validation of the dementia risk score using routinely collected data. BMC Med. 2016;14:6.

18. Iliffe S, Robinson L, Brayne C, Goodman C, Rait G, Manthorpe J, Ashley P. Primary care and dementia: 1. Diagnosis, screening and disclosure. Int J Geriatr Psychiatry. 2009;24(9):895-901.

19. Imfeld P, Pernus YBB, Jick SS, Meier CR. Epidemiology, co-morbidities, and medication use of patients with Alzheimer's disease or vascular dementia in the UK. J Alzheimers Dis. 2013;35:565-73.

20. Brown A, Kirichek O, Balkwill A, Reeves G, Beral V, Sudlow C, Gallacher J, Green J. Comparison of dementia recorded in routinely collected hospital admission data in England with dementia recorded in primary care. Emerg Themes Epidemiol. 2016;13:11.

21. Roland M. Linking physicians' pay to the quality of care - a major experiment in the United Kingdom. N Engl J Med. 2004;351:1448-54.

22. Gooley TA, Leisenring W, Crowley J, Storer BE. Estimation of failure probabilities in the presence of competing risks: new representations of old estimators. Stat Med. 1999;18:695-706.

23. Fine JP, Gray RJ. A proportional hazards model for the subdistribution of a competing risk. J Am Stat Assoc. 1999;94:496-509.

24. Rubin DB. Multiple imputation after 18+ years. J Am Stat Assoc. 1996;91:473-89.

25. Tully PJ, Hanon O, Cosh S, Tzourio C. Diuretic antihypertensive drugs and incident dementia risk: a systematic review, meta-analysis and metaregression of prospective studies. J Hypertens. 2016;34:1027-35.

26. Novak V, Hajjar I. The relationship between blood pressure and cognitive function. Nat Rev Cardiol. 2010;7:686-98.

27. Oveisgharan S, Hachinski V. Hypertension, executive dysfunction, and progression to dementia the Canadian study of health and aging. Arch Neurol. 2010;67:187-92.

28. Staessen JA, Thijs L, Richart T, Odili AN, Birkenhager WH. Placebo-controlled trials of blood pressure-lowering therapies for primary prevention of dementia. Hypertension. 2011;57:e6-7.

29. The SPRINT Research Group, Wright JT Jr, Williamson JD, Whelton PK, Snyder JK, Sink KM, Rocco MV, Reboussin DM, Rahman M, Oparil S, Lewis CE, Kimmel PL, Johnson KC, Goff DC, Fine LJ, Culter JA, Cushman WC, Cheung AF, Ambrosius WT. A randomized trial of intensive versus standard blood-pressure control. N Engl J Med. 2015;373:2103-16.

30. Freitag MH, Peila R, Masaki K, Petrovitch H, Ross GW, White LR, Launer LJ. Midlife pulse pressure and incidence of dementia: the Honolulu - Asia aging study. Stroke. 2006;37:33-07.

31. Marfella R, Paolisso G. Increased arterial stiffness trumps on blood pressure in predicting cognitive decline in low-risk populations. Hypertension. 2016;67:30-1.

32. Sacco RL, Benjamin EJ, Broderick JP, Dyken M, Easton JD, Feinberg WM, Goldstein LB, Gorelick PB, Howard G, Kittner SJ, Manolio TA, Whisnant JP, Wolf PA. American Heart Association prevention conference. IV. Prevention and rehabilitation of stroke. Risk factors. Stroke. 1997;28:1507-17.

33. Wolf PA, Dagostino RB, Oneal MA, Sytkowski P, Kase CS, Belanger AJ, Kannel WB. Secular trends in stroke incidence and mortality - the Framingham -study. Stroke. 1992;23:1551-5.

34. Brown RD, Whisnant JP, Sicks JD, OFallon WM, Wiebers DO. Stroke incidence, prevalence, and survival - secular trends in Rochester, Minnesota, through 1989. Stroke. 1996:27:373-80.

35. Palmer AJ, Bulpitt CJ, Fletcher AE, Beevers DG, Coles EC, Ledingham JGG, Oriordan PW, Petrie JC, Rajagopalan BE, Webster J, Dollery CT. Relation between blood-pressure and stroke mortality. Hypertension. 1992;20:601-5. 
36. Skoog I, Lernfelt B, Landahl S, Palmertz B, Andreasson LA, Nilsson L, Persson G, Oden A, Svanborg A. 15-year longitudinal study of blood pressure and dementia. Lancet. 1996;347:1141-5.

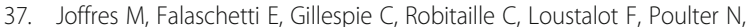
McAlister FA, Johansen H, Baclic O, Campbell N. Hypertension prevalence, awareness, treatment and control in national surveys from England, the USA and Canada, and correlation with stroke and ischaemic heart disease mortality: a cross-sectional study. BMJ Open. 2013;3:e003423.

38. Banerjee D, Chung S, Wong EC, Wang EJ, Stafford RS, Palaniappan LP. Underdiagnosis of hypertension using electronic health records. Am J Hypertens. 2012;25:97-102.

39. Rakotz MK, Ewigman BG, Sarav M, Ross RE, Robicsek A, Konchak CW, Gavagan TF, Baker DW, Hyman DJ, Anderson KP, Masi CM. A technologybased quality innovation to identify undiagnosed hypertension among active primary care patients. Ann Fam Med. 2014;12:352-8.

40. Hachinski V, Sposato LA. Dementia: from muddled diagnoses to treatable mechanisms. Brain. 2013;136:2652-4.

Submit your next manuscript to BioMed Central and we will help you at every step:

- We accept pre-submission inquiries

- Our selector tool helps you to find the most relevant journal

- We provide round the clock customer support

- Convenient online submission

- Thorough peer review

- Inclusion in PubMed and all major indexing services

- Maximum visibility for your research

Submit your manuscript at www.biomedcentral.com/submit
C) Biomed Central 